\title{
The place of perceived exertion ratings in exercise prescription for cardiac transplant patients before and after training
}

\author{
Roy J Shephard, T Kavanagh, D J Mertens, M Yacoub
}

\begin{abstract}
Objective-Heart rate provides a poor guide to exercise prescription after cardiac transplantation. This study explores whether the rating of perceived exertion (RPE) provides useful alternative information.

Methods-Borg's original categoric scale was applied to 36 male patients [ $T$, age 47(SD 9 years] as they performed a progressive cycle ergometer test an average of seven months (range two to 23 months) after cardiac transplantation. The test was repeated after 16(7) months of progressive exercise centred rehabilitation. Sedentary but healthy controls [C, $n=45$, age 45(7) years] performed a similar progressive cycle test.

Results-Initially, 13 RPE units corresponded to $66(12) \%$ of peak $\mathrm{VO}_{2}$ in $\mathrm{T}$ and $50(11) \%$ in C. Rehabilitation augmented peak $\mathrm{VO}_{2}$ (by 19\%) and estimated lean body mass (by $3.5 \%$ ) in the cardiac transplant patients. The increase of heart rate $(H R)$ at $13 \mathrm{RPE}$ units $[\Delta \mathrm{HR}=10(17)$ beats' $\mathrm{min}^{-1}$ ] showed moderate correlations with gains of lean mass $(r=0.72)$ and gains of peak $\dot{\mathrm{V}} \mathrm{O}_{2}(r=0.58)$. The relative oxygen intake at 13 RPE units remained unchanged at $68(12) \%$ of peak VंO

Conclusions-Large inter-individual variations of $\mathrm{RPE}$ at a given $\mathrm{VO}_{2}$ limit the value of perceived exertion in exercise prescription. Ratings seem best restricted to fine tuning fixed distance/fixed speed exercise prescriptions in patients undergoing rehabilitation after cardiac transplantation.

(Br F Sports Med 1996;30:116-121)
\end{abstract}

Key terms: Borg categoric scale; cardiac transplantation; exercise prescription; muscle weakness

There is neither anatomical nor functional evidence of cardiac reinnervation for the first 18-24 months following orthotopic heart transplantation. ${ }^{1-3}$ The heart rate shows a slower than normal increase with exercise, and plateau values are lower than in age matched peers with normally innervated hearts. ${ }^{4-7}$ Heart rates observed in laboratory exercise testing thus offer a somewhat fallible guide to exercise prescription in such individuals.

Borg ratings of perceived exertion $\left(\mathrm{RPE}^{8}\right)$ ranging from "fairly light" to "somewhat hard," 11-14 units on the original categoric scale, have been suggested as a possible alternative source of prescriptive information, ${ }^{4-15}$ although the ability to transfer a rating taken from a progressive laboratory test to free exercise such as walking seems rather limited, even in young adults with normal hearts. ${ }^{13} 1416$

We hypothesised that after cardiac transplantation the perceptions associated with a given intensity of exercise would be further distorted by a combination of anxiety and muscle wasting. ${ }^{5}$ Moreover, we anticipated that perceptions would normalise if anxiety was reduced and lean body mass and peak oxygen consumption $\left(\mathrm{VO}_{2}\right)$ were restored by participation in an exercise centred rehabilitation programme. To test the impact of such training induced changes upon RPE, we evaluated the responses of 36 cardiac transplant patients to a progressive laboratory cycle ergometer test when they were first admitted to our rehabilitation programme, an average of seven months after a súccessful orthotopic heart transplantation. The observations were repeated 16 months later, when all of the group had successfully completed a progressive, exercise centred rehabilitation process, with substantial increases in their lean tissue mass and peak $\mathrm{VO}_{2}$. The patients' initial and final ratings of exertion were compared with the perceptions of sedentary but otherwise healthy subjects of similar age who performed an identical progressive cycle ergometer test.

\section{Methods}

SUBJECTS

Tests were conducted under conditions approved by the institutional human experimentation review committee. The clinical sample comprised 36 male volunteers, aged 47(SD 9) years. All had undergone a successful orthotopic cardiac transplantation at Harefield Hospital, Middlesex, UK, an average of seven months earlier. Entry dates ranged quite widely, from two to 23 months after operation, but a comparison of early with late entrants did not disclose any significant differences in either initial exercise responses or responses to training between the two categories of subject. At the time of initial testing, all participants were in good clinical health, with good cardiac function and no signs of transplant rejection. They were all receiving the customary Harefield immunosuppressant drug regimen, as detailed previously5: small maintenance 
doses of cyclosporin and/or imuran, as well as dipyridamole $(300 \mathrm{mg} / \mathrm{d})$ and one multivitamin capsule per day. Acyclovir and nystatin were prescribed when required. None of the 36 study participants was receiving $\beta$ blocking agents. Other prescribed medications included low doses of prednisone $(5-15 \mathrm{mg} / \mathrm{d}$ in eight subjects), frusemide $(20-80 \mathrm{mg} / \mathrm{d}$ in 11 subjects), hydralazine $(25-250 \mathrm{mg} / \mathrm{d}$ in nine subjects), and nifedipine (10-40 $\mathrm{mg} / \mathrm{d}$ in six subjects). In a few instances, it was necessary for the physician to change the quantity of prescribed medications over the $16(7)$ months of observation.

The control subjects were 45 sedentary but otherwise healthy male volunteers. Their average age [45(7) years] was similar to that of the cardiac transplant patients.

\section{EXPERIMENTAL PLAN}

The patients performed a progressive cycle ergometer test when they were first seen, and again after an average of 16(7) months of rehabilitation with an endurance training focus. Practical constraints limited the testing of the control subjects to a single session, performing the same progressive cycle ergometer test. However, others have shown that in the absence of training, cycle ergometry RPE values remain stable across trials, whether the work rate is imposed by the observer ${ }^{15}$ or is determined by the subject. ${ }^{14}$ In both subject groups, the submaximal portion of the test was used to explore relationships between RPE, ${ }^{8}$ heart rate, power output, and $\mathrm{VO}_{2}$ over the normally used prescriptive range, $11,12,13$, and 14 RPE units.

\section{TEST PROCEDURE}

A progressive exercise test was carried out on an electrically braked cycle ergometer (Elema Schonander). The intent was to exhaust the subject in 9-11 minutes. The subjects were asked to maintain a constant pedalling rate of 60 revolutions $\cdot \mathrm{min}^{-1}$, and beginning at a loading of $17 \mathrm{~W}$, the power output was increased by a further $17 \mathrm{~W}$ in each successive minute of testing. Criteria for halting the test were a plateau of $\mathrm{VO}_{2}$ (an increase in oxygen intake of less than $2 \mathrm{ml} \cdot \mathrm{kg}^{-1} \cdot \mathrm{min}^{-1}$ with a further increase of power output), an RPE of 19-20 units, inability to maintain the required pedalling cadence, and subjective exhaustion.

Ratings of the overall perception of effort were made using a cardboard replica of the original Borg categoric scale. ${ }^{8}$ Standard instructions were given before each test began. The subject used an index finger to signal at the end of each minute of exercise his current perception of "how hard does the exercise seem for the body as a whole?" In cases where subjects failed to signal one of the four required RPE values, the corresponding heart rate, power output and $\dot{\mathrm{VO}}_{2}$ were estimated by interpolation from the other RPE values.

The heart rate was determined from a continuously recorded electrocardiogram (unipolar CM5 leads), and the corresponding $\mathrm{VO}_{2}$ was monitored every $30 \mathrm{~s}$, using a Horizon II
Metabolic Cart (Sensor-Medics), calibrated against chemically analysed cylinder gas mixtures.

\section{BODY COMPOSITION}

The percentage of body fat was estimated from the thickness of triceps, subscapular, and suprailiac skinfolds, measured as described by Weiner and Lourie, ${ }^{17}$ with application of the appropriate age specific prediction equations of Durnin and Womersley ${ }^{18}$ and Siri. ${ }^{19}$ Lean body mass was estimated from the difference between total body mass and fat mass.

\section{TRAINING PROGRAMME}

Exercise prescription followed the standard Toronto Rehabilitation Centre pattern. ${ }^{20}$ In brief, patients were given a walking distance and pace based on responses to the progressive exercise test. They progressed from walking $1.6 \mathrm{~km}$ five times per week, to walking $6.5 \mathrm{~km}$ per session for a total of $32.5 \mathrm{~km}$ per week. The intensity of effort was held just below the ventilatory threshold $(60-70 \%$ of peak $\mathrm{VO}_{2}$ ). As an individual's physical condition improved, the pace was increased to maintain the required intensity of exercise. When the speed had increased to $9 \mathrm{~min} \cdot \mathrm{km}^{-1}$, slow jogging was introduced, initially in intervals of $50 \mathrm{~m}$ every $200 \mathrm{~m}$, until in some patients the entire $6.5 \mathrm{~km}$ distance was covered in $48 \mathrm{~min}$ five times per week.

Each session of endurance exercise was preceded by a $15 \mathrm{~min}$ muscle stretching routine, and the programme concluded with a 5 min easy "cool down" walk. Since patients were scattered widely across England, they followed the "out of town" routine developed by the Toronto Rehabilitation Centre. Normally, they trained on their own, using our standard exercise diaries to record distance, time, pre- and post-session pulse rates, Borg units of perceived exertion, and other comments regarding their work outs. Patients were seen every two to three months; diary records were then reviewed, exercise tests were repeated, exercise techniques were discussed, and advice was offered on any difficulties that were being encountered.

\section{STATISTICAL ANALYSIS}

Differences between means were evaluated by independent or paired two tailed $t$ tests, and $95 \%$ confidence intervals $(\mathrm{CI})$ were calculated where appropriate. Coefficients of correlation and linear regressions relating perceptions of effort and physiological variables (heart rate, power output, and oxygen consumption) were fitted by the method of least squares. Values are means(SD) unless otherwise stated.

\section{Results}

PHYSICAL CHARACTERISTICS AND TRANNING RESPONSE

The control subjects had an average height of $1.76(\mathrm{SD} 0.07) \mathrm{m}$, a total body mass of $80.7(10.9) \mathrm{kg}$, and a lean body mass of $62 \cdot 6(7 \cdot 6) \mathrm{kg}$. They reached a peak $\dot{\mathrm{VO}}_{2}$ of $34 \cdot 0(5 \cdot 9) \mathrm{ml} \cdot \mathrm{kg}^{-1} \cdot \mathrm{min}^{-1}$ during the progressive cycle ergometer test. 
The height of the patients was similar to that of the controls [1.72(0.06) $\mathrm{m}]$, but their body mass was only $69.9(11.5) \mathrm{kg}$, and their lean body mass $[56 \cdot 2(7 \cdot 4) \mathrm{kg}$ ] was $6 \cdot 6(1 \cdot 4) \mathrm{kg}$ less than that of the controls $(P<0.001)$. Their initial peak $\dot{\mathrm{V}} \mathrm{O}_{2}\left[21 \cdot 7(4 \cdot 5) \mathrm{ml} \cdot \mathrm{kg}^{-1} \cdot \mathrm{min}^{-1}\right]$ was also lower than that of the controls $(\mathbf{P}<0.001)$.

After 16 months of endurance centred training and rehabilitation, the peak $\mathrm{VO}_{2}$ of the patients increased by an average of $19.5 \%$ $(\mathrm{P}<0 \cdot 001)$, to $25 \cdot 8(6 \cdot 4) \mathrm{ml} \cdot \mathrm{kg}^{-1} \cdot \mathrm{min}^{-1}$. The body mass also increased by $5.7 \%$, to $73.9(12.4) \mathrm{kg}$ ( $\Delta$ body mass by paired $t$ test $=3.5(4.7) \mathrm{kg}, P<0.001)$, and the lean mass increased by an average of $3.5 \%$, to $58 \cdot 2(7 \cdot 5) \mathrm{kg}[\Delta$ lean body mass $=2 \cdot 0(3 \cdot 8) \mathrm{kg}$, $\mathrm{P}<0.001]$.

RELATION OF RPE TO HEART RATE

Probably because of the short $(1 \mathrm{~min})$ increments in the progressive test protocol, the heart rate of the control subjects averaged only 115 (16) beats $\mathrm{min}^{-1}$ at $13 \mathrm{RPE}$ units (fig 1), substantially below the anticipated steady state value $^{8}$ for "middle aged adults" of 130 beats. $\mathrm{min}^{-1}(P<0.001)$.

The heart rate of the cardiac transplant patients at a rating of $13 \mathrm{RPE}$ units was similar, at $111(14)$ beats $\cdot \mathrm{min}^{-1}$. However, after 16 months of rehabilitation, the heart rate corresponding to $13 \mathrm{RPE}$ units had increased significantly to $122(18)$ beats $\cdot \min ^{-1}(\Delta 10(17)$ beats $\cdot \mathrm{min}^{-1}, \quad 95 \%$ CI 4-16 beats $\mathrm{min}^{-1}$, $P<0.01$ )

RELATION OF RPE TO POWER OUTPUT

When the cardiac transplant patients were first seen, their perception of $13 \mathrm{RPE}$ units corresponded to an average power output of only $59(19) \mathrm{W}$, as compared to $91(34) \mathrm{W}$ in the age matched normal controls (fig 2), the difference between the two values [32(SEM 4) W] being highly significant $(P<0.001)$.

After the period of 16 months of rehabilitation, the power output of the patients at a



Figure 1 Relation of heart rate (beats $\cdot$ min-1) to rating of perceived exertion, using the original Borg (11) scale. Values are means, bars $=$ SEM, of data for 36 male heart transplant patients (before and after 16 months of endurance training), and for 45 male controls of similar age.

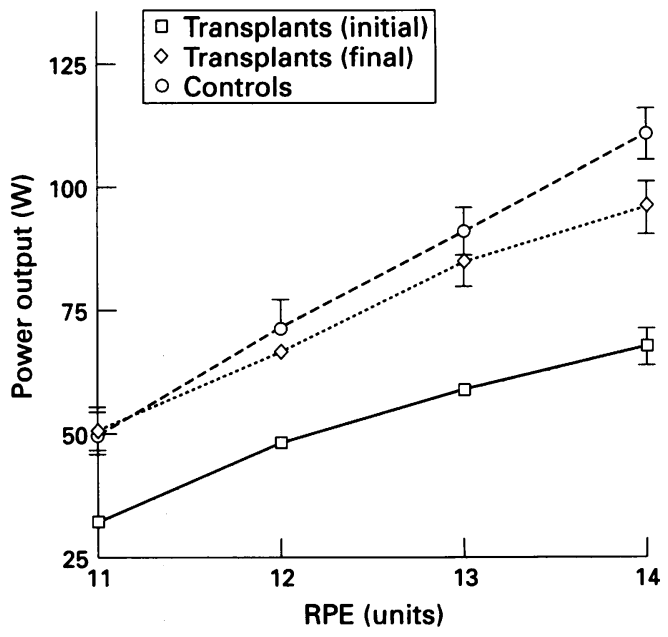

Figure 2 Relation of cycle ergometer power output (W) to rating of perceived exertion, using the original Borg (11) scale. Values are means, bars = SEM, of data for 36 male heart transplant patients (before and after 16 months of endurance training), and for 45 male controls of similar age.

rating of 13 units had increased substantially, to an average of $85(30) \mathrm{W}[\Delta=26($ SEM 5$) \mathrm{W}$, $95 \% \mathrm{CI} 16$ to $37 \mathrm{~W}, \mathrm{P}<0.001]$. The final ratings fell very close to the line set by the control subjects (fig 2).

RELATION OF RPE TO OXYGEN INTAKE

In the cardiac transplant patients, $13 \mathrm{RPE}$ units initially corresponded to a $\dot{\mathrm{VO}}_{2}$ of $14 \cdot 3(3 \cdot 6) \mathrm{ml} \cdot \mathrm{kg}^{-1} \cdot \mathrm{min}^{-1}$. After 16 months of rehabilitation, the $13 \mathrm{RPE}$ unit value had increased to $17 \cdot 3(5 \cdot 1) \quad \mathrm{ml} \cdot \mathrm{kg}^{-1} \cdot \mathrm{min}^{-1} \quad[\Delta$ $2 \cdot 9(4 \cdot 6) \mathrm{ml} \cdot \mathrm{kg}^{-1} \cdot \mathrm{min}^{-1}, \mathrm{P}<0 \cdot 001,95 \% \mathrm{CI} 1 \cdot 2$ to $4.6 \mathrm{ml} \cdot \mathrm{kg}^{-1} \cdot \mathrm{min}^{-1}$, fig 3]. The average $\dot{\mathrm{VO}}_{2}$ at an RPE of 13 units was now very similar to that of the age matched normal subjects $[17 \cdot 0(1 \cdot 9)$ $\left.\mathrm{ml} \cdot \mathrm{kg}^{-1} \cdot \mathrm{min}^{-1}\right]$, although the final peak $\dot{\mathrm{VO}}{ }_{2}$ of the patients [an average of $25 \cdot 8(6 \cdot 4)$ $\mathrm{ml} \cdot \mathrm{kg}^{-1} \cdot \mathrm{min}^{-1}$ ] was still only $76 \%$ of that seen in the controls.

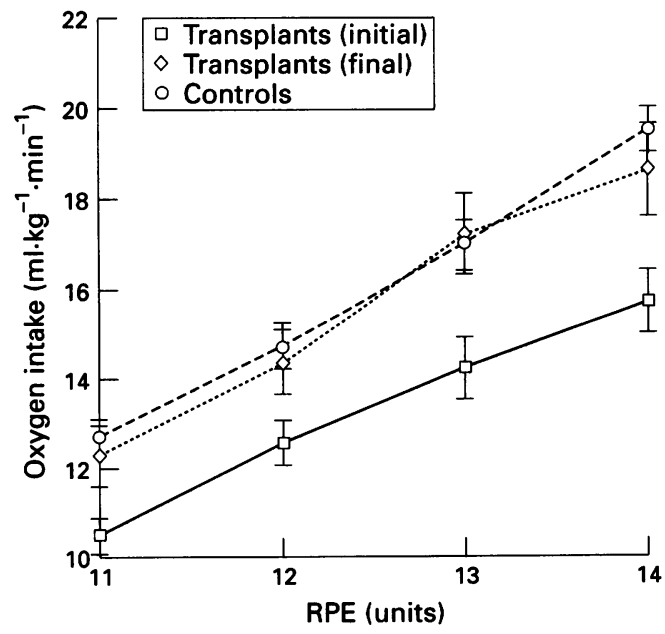

Figure 3 Relation of $\dot{V} O 2(\mathrm{ml} \cdot \mathrm{kg}-1 \cdot \mathrm{min}-1)$ to rating of perceived exertion, using the original Borg (11) scale. Values are means, bars = SEM, of data for 36 male heart transplant patients (before and after 16 months of endurance training) and for 45 male controls of similar age. 


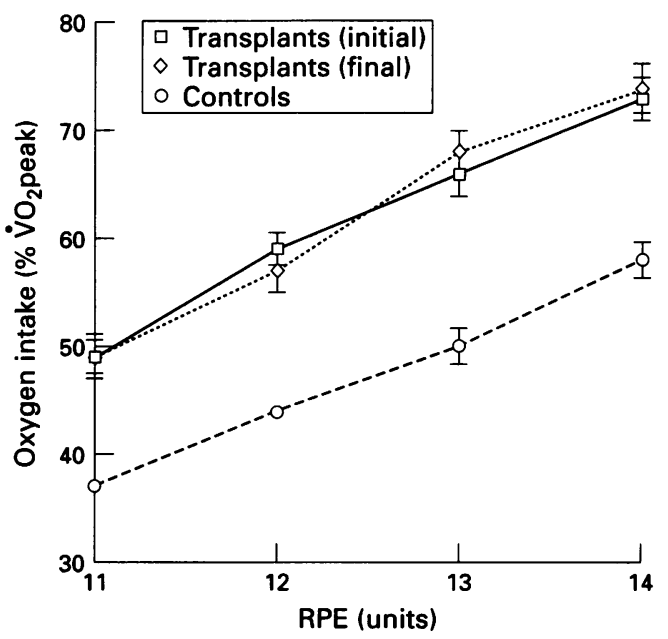

Figure 4 Relation of oxygen intake (percent of peak $\dot{\mathrm{V}} \mathrm{O}_{2}$ ) to rating of perceived exertion, using the original Borg (11) scale. Values are means, bars = SEM, of data for 36 male transplant patients (before and after 16 months of training) and for 45 male controls.

RELATION OF RPE TO PERCENTAGE OF PEAK OXYGEN INTAKE

The cardiac transplant patients initially reported an RPE of 13 units at $66 \cdot 3(11 \cdot 6) \%$ of peak $\mathrm{VO}_{2}$ (fig 4). After 16 months of rehabilitation, the average response to a rating of $13 \mathrm{RPE}$ units showed little change [an average of $68 \cdot 0(12 \cdot 2) \%$ of peak $\mathrm{VO}_{2}$ ]. Values at $13 \mathrm{RPE}$ units were substantially lower in the age matched normal controls [50.4(10.5)\% of

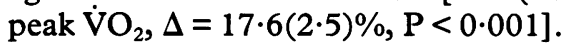

\section{INFLUENCE OF LEAN BODY MASS}

The training related increase in heart rate of the cardiac transplant patients at an overall RPE of 13 units showed a moderate coefficient of correlation with both the gain in lean body mass $(r=0.72)$ and with the gain in peak $\mathrm{VO}_{2}$ $(r=0.58)$, although the difference between the two correlation coefficients was not statistically significant with the available sample size.

\section{Discussion}

BASIS OF RPE PRESCRIPTIONS

Borg $^{8}$ originally constructed his categoric RPE scale with the intent that the steady state heart rate response of a "normal, healthy middle aged man" (his subjects were aged 20-40 years) could be estimated on multiplying the rating by a factor of 10 . A rating of 13 Borg RPE units ("somewhat hard") or a range of ratings (for example, 12-14 units) has commonly been thought to define a safe but effective intensity of aerobic exercise, with a heart rate in the training zone, just below the ventilatory threshold. ${ }^{11}$

In fact, the overall perception of the intensity of effort is a complex gestalt of cognitively integrated sensations arising in the working muscles, tendons and joints, the blood stream, the heart, the lungs, the skin, and the higher centres of the brain. ${ }^{21-23}$ Given this multiplicity of inputs, it is not surprising either that there are differences of perceptions between steady state and progressive exercise tests, or that ratings can be influenced by muscle strength.
In developing the original scale, Borg's implicit assumption was a resting heart rate of 60 beats $\cdot \mathrm{min}^{-1}$ and a peak heart rate of 200 beats $\mathrm{min}^{-1}$. Cardiac transplant patients operate over a narrower range, and the heart rate increases slowly during exercise. ${ }^{4}$ In our study, the span was from 104(12) to $136(15)$ beats $\cdot \mathrm{min}^{-1}$; with our progressive test protocol, an effort of 50-70 W (corresponding to an RPE of 13 units) was reached after three to four minutes of exercise, giving a fair opportunity for development of a humorally mediated tachycardia. Heart rates at 13 RPE units were superficially similar to those seen in our age matched control subjects; however, because of high resting heart rates, the delta heart rate corresponding to $13 \mathrm{RPE}$ units was much smaller in the cardiac transplant patients (7 beats $\mathrm{min}^{-1}$ ) than in the normal individuals ( 38 beats $\cdot \min ^{-1}$ ).

RELATION OF RPE TO PERCENTAGE OF PEAK VंO In the patients, $13 \mathrm{RPE}$ units corresponded to $66(12) \%$ of peak $\mathrm{VO}_{2}$ before rehabilitation, and to $68(12) \%$ after 16 months of rehabilitation, whereas in the normal subjects, $13 \mathrm{RPE}$ units were reported at only $50 \cdot 4(10 \cdot 5) \%$ of peak $\dot{\mathrm{VO}}_{2}$.

One reason why the cardiac transplant patients exploited a larger fraction of peak $\mathrm{VO}_{2}$ at a given RPE may be that they had only a limited heart rate reserve (an average of 32 beats $\cdot \mathrm{min}^{-1}$ before training and 48 beats $\cdot \mathrm{min}^{-1}$ after training, compared with 99 beats $\cdot \mathrm{min}^{-1}$ in the age matched controls). Patients who have undergone cardiac transplantation also perform a larger fraction of vigorous exercise anaerobically. ${ }^{7}$ Thus $13 \mathrm{RPE}$ units corresponded to $43 \%$ of peak power output for both subject groups.

The laboratory testing was based on cycle ergometry. Because of local loading of the quadriceps, both muscle specific and overall ratings of effort tend to be higher in relation to percentage of peak $\dot{\mathrm{VO}}_{2}$ during cycling than during walking, jogging, or treadmill exercise, ${ }^{24}$ and sensitivity to muscle weakness is enhanced unless the subject is accustomed to cycling. ${ }^{8}$

TRAINING AND RPE OF CARDIAC TRANSPLANT PATIENTS

Following training, the transplant patients showed a substantial and statistically significant upward displacement of the line relating heart rate to readings on the Borg scale. However, as also noted by Ehrman et al, ${ }^{25}$ when ratings were related to percentage of peak $\mathrm{VO}_{2}$, there was no significant change over the course of rehabilitation. The apparent paradox of an increase in exercise heart rate but not in relative oxygen intake at a given $R P E$ is explained if the heart rate before and after rehabilitation is calculated as a fraction of the corresponding heart rate reserve.

A progressive recovery from major surgery could conceivably account for a part of the time related increase in peak heart rate, ${ }^{26}$ although we have seen relatively little difference in pretraining data between early and late entrants to our rehabilitation programme. A 
second possible explanation is a training related strengthening of the skeletal muscles, with a resultant reduction of both cardiac afterloading and local muscular fatigue. In such a situation, the patient would be able to exercise for longer. This might allow longer time for catecholamines to exert a positive chronotropic effect, although, contrary to this potential explanation, Ehrman et $a l^{27}$ found no increase of peak heart rate despite higher plasma noradrenaline levels when cardiac transplant patients were allowed six rather than three minutes per exercise test stage.

We had hypothesised that the heart rate corresponding to a given overall RPE rating would increase as the skeletal muscles of the cardiac transplant patients were strengthened by the rehabilitation programme. We did not have opportunity to evaluate either muscle strength or differentiated sensations. However, given the close correlation between peak muscle force and muscle cross section, ${ }^{28}$ we decided to examine the relations of the increment in heart rate at an RPE of 13 units to gains of lean body mass and peak $\mathrm{VO}_{2}$. The association tended to be closer for gains of lean body mass than for gains of peak $\mathrm{VO}_{2}$ (fig 5), although the difference between the two correlation coefficients was not statistically significant (in part because of sample size, and in part because of limitations to skinfold estimates of lean mass, particularly in the patients who were receiving steroids).

Nevertheless, the present findings support the view that muscle wasting increases perceptions of effort in the months immediately following cardiac transplantation. Rehabilitation programmes following cardiac transplantation should thus include specific exercises to restore lean tissue, countering the effects of prolonged bed rest and possible immunosuppressive corticosteroid treatment.

USEFULNESS OF RPE PRESCRIPTION AFTER CARDIAC TRANSPLANTATION

Despite the potential for distortion of the RPE by a slow heart rate on-transient, an increase of peak heart rate with training, and possible strengthening of initially weak leg muscles, the

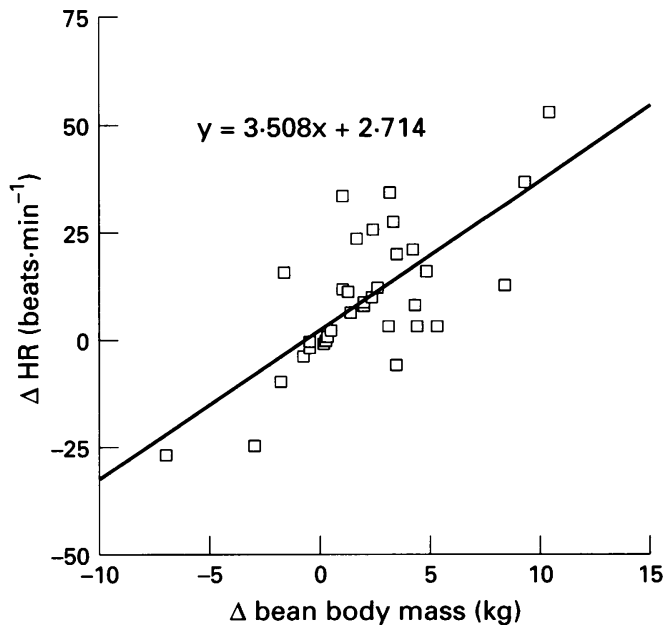

average cardiac transplant patient develops an appropriate intensity of exercise when exercising on the cycle ergometer at an RPE of 12 to 13 units, both before and after training. Keteyian $e t a^{29}$ reported similar findings for 15 patients who were first seen some 12 weeks after surgery; they argued that the RPE could be used safely to regulate training intensity despite a shift in the $\mathrm{RPE} /$ heart rate relation over 11 weeks of rehabilitation.

As in normal individuals, ${ }^{16}$ the main difficulty in using RPE to regulate exercise intensity is not the average response, but rather the large variation in individual perceptions of a given relative intensity of effort. At an RPE of 13 units, the SD amounted to around $12 \%$ of peak $\mathrm{VO}_{2}$. The practical implication is that if patients are advised to exercise at an RPE of 13 units, at least one person in 40 will reach a dangerously high $90 \%$ of peak $\dot{\mathrm{VO}}_{2}$, and a further one in 40 will exercise at an ineffectively low $42 \%$ of peak $\dot{\mathrm{VO}}_{2}$. If an $\mathrm{RPE}$ range is prescribed (for example, 12-14 units), and the production of effort is transferred from a laboratory cycle ergometer to walking or jogging in the field, then the spread of attained oxygen consumptions will be even larger.

Possibly, the variance of exercise intensity could be reduced if patients were taken repeatedly to their ventilatory threshold in the cardiac laboratory, and were then asked to reproduce the corresponding perception of effort when filling their prescription. However, even if such an approach did prove more precise, it is doubtful if most laboratories would have the time and personnel needed for repeated instruction in use of the RPE. Plainly, the standard RPE must be used in conjunction with other prescriptive measures if some patients are not to adopt either an excessive or an ineffective intensity of exercise.

The Toronto Rehabilitation Centre has for more than 20 years used the time required to cover a fixed walking distance as the dominant component of a personal endurance fitness exercise prescription. ${ }^{20}$ The required value is established as a percentage of the directly measured peak oxygen intake or the oxygen intake at the ventilatory threshold. This mode

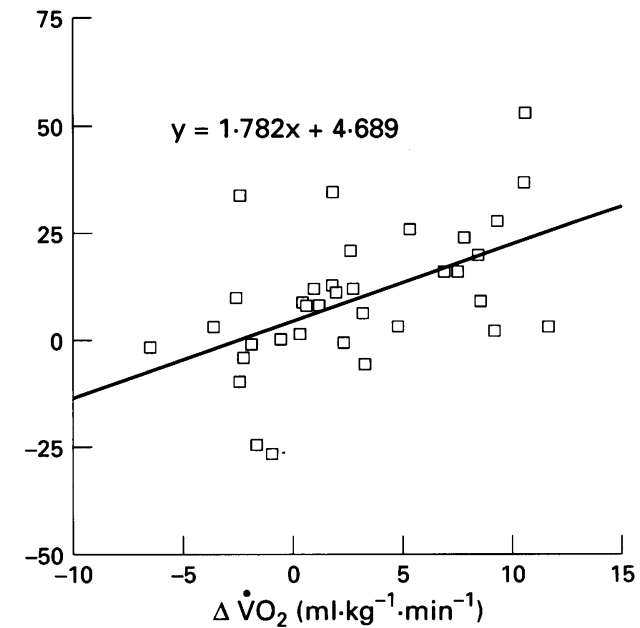

Figure 5 Influence of 16 months rehabilitation on heart rate $(H R)$ at RPE of 13 Borg units. $\triangle H R$ in relation to delta lean body mass (left) and $\Delta$ peak $\dot{V O}_{2}$ (right); equations show linear regressions fitted by the method of least squares. 
of prescription has proved remarkably safe and effective in the training of more than 10000 patients with a variety of cardiac disorders. ${ }^{20}$ We believe it is particularly appropriate after cardiac transplantation. Certainly, it has allowed us to train the present group of 36 cardiac transplant patients safely, with a substantial gain in peak $\dot{\mathrm{VO}}_{2}{ }^{5}$ In our experience, ratings of perceived exertion are best used not to set the intensity of effort, but rather to fine tune responses to a walking pace prescription in the face of adverse environmental conditions or a change in clinical condition.

\section{CONCLUSIONS}

On average, cardiac transplant patients develop an appropriate intensity of training exercise, both before and after participation in a rehabilitation programme, when undertaking a progressive cycle ergometer test at an RPE of 13 units. However, the practical application of this finding to exercise prescription is limited by differences of perceptions relating to exercise mode and environment, and more importantly by a very large interindividual variation in perceptions. Use of the RPE should thus be limited to the fine tuning of prescriptions that are based primarily upon distance and the speed of fast walking or jogging.

Our thanks are due to Mr Salah Qureshi MSc, of the Toronto Rehabilitation Centre, for his technical assistance. The research of one of us (RJS) is supported in part by a research grant from Canadian Tire Acceptance Limited.

1 Bexton RS, Milne JR, Cory-Pearce R, English TAH, Camm AJ. Effects of beta-blockade on exercise response after cardiac transplantation. Br Heart $\mathcal{F}$ 1983;49:584-8.

2 Borow KM, Neumann A, Arensman FW, Yacoub MH. Lef ventricular contractility and contractile reserve in humans ventricular contractility and contractile reserve in humans
after cardiac transplantation. Circulation 1985;71: after card

3 Wilson RF, Christensen BV, Olivari MT, Simon A White C, Laxson DD. Evidence for structura sympathetic reinnervation after orthotopic cardiac transplantation. Circulation 1991;83:1210-20.

4 Kavanagh T. Exercise and therapy of the cardiac transplant patient. In: RJ Shephard, $\mathrm{H}$ Miller, eds. Exercise and the heart in health and disease. New York: Marcel Dekker, 1992: 257-82.

5 Kavanagh T, Yacoub MH, Mertens DJ, Kennedy J, Campbell RB. Cardio-respiratory responses to exercise training after orthotopic cardiac transplantation. Circulation 1988;77:162-71.

6 Pflugfelder PW, Purves PD, McKenzie FN, Kostuk WJ. Cardiac dynamics during supine exercise in cyclosporine treated orthotopic heart transplant recipients: assessments by radionuclide angiography. $\mathcal{f} A m$ Coll Cardiol 1987; 10:336-41.

7 Savin WM, Haskell WL, Schroeder JS, Stinson EB. Cardiorespiratory responses of cardiac transplant patients to graded symptom-limited exercise. Circulation 1980;62: 55-60.

8 Borg G. The perception of physical performance. In: Shephard RJ, ed. Frontiers of fitness. Springfield, IL: CC Thomas, 1971:280-94

9 Noble BJ. Clinical applications of perceived exertion. Med Sci Sports Exerc 1982;14:406-11.

10 Chow RJ, Wilmore JH. The regulation of exercise intensity by ratings of perceived exertion. $\mathcal{f}$ Cardiac Rehabil 1984;4:382-7.

11 American College of Sports Medicine. Guidelines for exercise testing and prescription, 4th ed. Philadelphia: Lea \& Febiger, 1991:69-71.

12 Glass SC, Knowlton RG, Becque MD. Accuracy of RPE from graded exercise to establish exercise training intensity. Med Sci Sports Exerc 1992;24:1303-7.

13 Ceci R, Hassmén P. Self-monitored exercise at three different RPE intensities in treadmill vs field running. Med Sci Sports Exerc 1991;23:732-8.

14 Dunbar C, Robertson RJ, Baun R, Blandin MF, Metz K, Burdett $R$, et al. The validity of regulating exercise Burdett $\mathrm{R}$, et al. The validity of regulating exercise
intensity by ratings of perceived exertion. Med Sci Sports Exerc 1992;24:94-9.

15 Birk TJ, Birk C. Use of ratings of perceived exertion for exercise prescription. Sports Med 1987;4:1-8.

16 Shephard RJ, Vandewalle H, Gil V, Bouhlel E, Monod H. Respiratory, muscular and overall perceptions of effort the influence of hypoxia and muscle mass. Med Sci Sports Exerc 1992;24:556-67.

17 Weiner JS, Lourie JA. Practical human biology. London: Academic Press, 1981:87-97.

18 Durnin JVGA, Womersley J. Body fat assessed from total body density and its estimation from skinfold thickness: measurements on 481 men and women aged from 16 to 72 years. Br $\mathfrak{f}$ Nutr 1974;32:77-97.

19 Siri WE. The gross composition of the body. Adv Biol Med Phys 1956;4:239-80.

20 Kavanagh $\mathrm{T}$. The healthy heart program. Toronto: Van Nostrand, 1980:111-36.

21 Williams JG, Eston RG. Determination of the intensity dimension in vigorous exercise programmes with particular reference to the use of the rating of perceived exertion. Sports Med 1989;8:177-89.

22 Cafarelli E. Sensory processes and endurance performance. In: Shephard RJ, Astrand P-O, eds. Endurance in sport Oxford: Blackwell Scientific Publications, 1992:261-9.

23 Watt B, Grove R. Perceived exertion. Antecedents and applications. Sports Med 1993;15:225-41.

24 Hetzler RK, Seip RL, Boutcher SH, Pierce E, Snead D, Weltman A. Effect of exercise modality on ratings of perceived exertion at various lactate concentrations. Med Sci Sports Exerc 1991;23:88-92.

25 Ehrman J. Keteyian S, Fedel F, Rhoads K, Levine B, Shepard R. Ventilatory threshold after exercise training in orthotopic heart transplant recipients. $\mathcal{f}$ Cardiopulm Rehabil 1992;12:126-30.

26 Rudas L, Pflugfelder PW, Menkis AH, Novick RJ McKenzie FN, Kostuk WJ. Evolution of heart rate responsiveness after orthotopic cardiac transplantation. Am f Cardiol 1991;68:232-6.

27 Ehrman J, Keteyian S, Fedel F, Elder L, Kataoka T. Heart rate and catecholamine responses of heart transplant patients to standard and extended duration exercise tests [abstr]. Med Sci Sports Exerc 1992;24:S85.

28 Maughan RJ, Watson JS, Weir J. Relationship between muscle strength and muscle cross-sectional area in male sprinters and endurance runners. Eur f Appl Physiol 1983;50:309-18.

29 Keteyian S, Ehrman J, Fedel F, Rhoads K. Heart-rate perceived exertion relationship during exercise in orthotopic heart transplant patients. $\mathcal{F}$ Cardiopulm Rehabil 1990;10:287-93. 